\title{
Zukunftsschau IAA
}

\section{Liebe Leserin, lieber Leser,}

die Automobilbranche befindet sich in einer überaus spannenden Phase. Die Schlagworte des Wandels sind längst nicht mehr nur in der Fachpresse allgegenwärtig. Digitalisierung, autonomes Fahren, Elektrifizierung und neue Mobilitätskonzepte, zunehmende Komplexität und Vielfalt der Antriebsstränge. All das wird begleitet von der vehementen und teils hitzigen Diskussion um die Zukunft des Dieselmotors. Doch damit nicht genug: Die jüngsten Kartellvorwürfe bergen enormes Schadenspotenzial für die deutschen OEMs, die sich selbst so gerne die Technologieführerschaft attestieren.

Darüber hinaus sind völlig neue Player auf den Markt getreten, die vor einer Dekade nur kühnste Visionäre als Schlüsselfiguren der Automobilbranche vermutet hätten. Wer rechnete vor zehn Jahren ernsthaft damit, dass Facebook einmal auf der IAA vertreten sein wird?

So schaut die Branche auch 2017 wieder mit Spannung nach Frankfurt am Main, wenn dort im Schatten von Messeturm und Festhalle zum 67. Mal das automobile Herz der Welt schlägt. Denn hier soll die Zukunft spürbar, ja fühlbar gemacht werden. Entsprechend hat sich die IAA in diesem Jahr das Motto „Zukunft erleben“ gegeben. Insofern war es natürlich auch für uns naheliegend, den Fokus dieser ATZextra auf die Zukunftsthemen der Branche zu legen.

Für viele Besucher bestimmen in erster Linie die Hersteller und Zulieferer, die ihre Neuheiten auf dem Frankfurter Parkett zeigen, das Bild der automobilen Zukunft. Auch wenn in diesem Jahr einige bekannte Namen, wie Renault, Nissan oder Volvo fehlen, können sich die Besucher über spannende Neuerscheinungen, Facelifts, technische Innovationen und die neuesten digita- len Errungenschaften freuen. Einige davon werden Ihnen auch in diesem Sonderheft wiederbegegnen.

Ein wichtiger Teil der automobilen Zukunft dreht sich aber nicht um Treibstoff und Motoren, sondern um Bits und Bytes, Digitalisierung, künstliche Intelligenz und Vernetzung. Diese Entwicklung des Automobils als Teil des Internets der Dinge beeinflusst auch das neue Verhältnis zwischen klassischen Autoproduzenten und IT-Firmen. Auch hier bleibt die Zukunft dynamisch und spannend. Die hohe Zahl an Kooperationen, Übernahmen und Joint Ventures in den letzten Jahren beweist das eindrucksvoll. Die Verflechtungen dürften künftig noch zunehmen. Eine Plattform dafür ist auch die zum zweiten Mal stattfindende New Mobility World. Dort zeigen Automobilindustrie und Start-ups, wie sie sich die Zukunft der Mobilität vorstellen.

Unsere Redaktion wünscht Ihnen eine angenehme und aufschlussreiche Lektüre. Wir sehen uns auf dem Frankfurter Messeparkett.

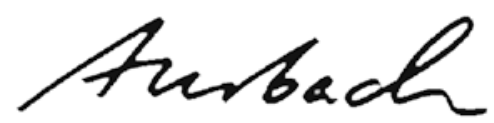

Benjamin Auerbach,

Editorial Manager Corporate Solutions

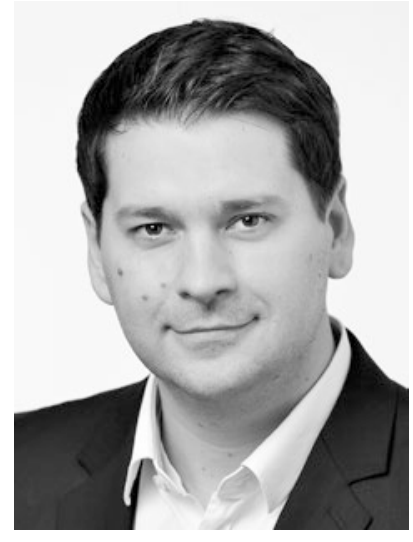

